\title{
Genética das Distonias
}

\author{
Patrícia Maria de Carvalho Aguiar* \\ Henrique Ballalai Ferraz**
}

\section{RESUMO}

As síndromes distônicas apresentam uma grande variabilidade clínica e genética. Hoje, existe uma tendência crescente à classificação genética das formas hereditárias de distonia. $\mathrm{O}$ avanço das técnicas de biologia molecular vem permitindo o mapeamento genético e alguns tipos de distonia já tiveram os seus respectivos genes identificados, como a distonia primária ligada ao DYT1 e a distonia doparresponsiva. Apresentamos uma breve revisão sobre os aspectos clínicos e genéticos de algumas formas hereditárias de distonia, enfatizando aquelas nas quais a distonia apresenta-se como sintoma único ou predominante.

\section{UNITERMOS}

Distonia, genética, DYT1, distonia doparresponsiva.
* Mestra em Neurologia pela Escola Paulista de Medicina - Unifesp.

** Doutor em Neurologia e Chefe do Setor de Distúrbios do Movimento da Disciplina de Neurologia da Escola Paulista de Medicina - Unifesp.
Distonia é uma síndrome caracterizada por movimentos involuntários provocados por uma contração muscular sustentada, levando à torção, a movimentos repetitivos ou a posturas anormais. Os movimentos podem acometer qualquer parte do corpo, incluindo as musculaturas axial, cranial e dos membros ${ }^{1}$.

O termo distonia foi utilizado pela primeira vez por Oppenheim, em 1911, ao descrever uma doença iniciada na infância e caracterizada por espasmos musculares tônicos e clônicos em diferentes partes do corpo. À essa doença ele deu o nome de "distonia muscular deformante" 2 . Prefere-se, hoje, nomear essa entidade como "distonia de torção primária", pois o fenômeno não tem origem muscular como Oppenheim supunha. Na prática, o termo distonia tanto tem sido utilizado para nomear o tipo de movimento anormal (sinal clínico) como para caracterizar a síndrome na qual esses movimentos anormais predominam.

As distonias representam um grupo de doenças com grande variabilidade clínica e genética. Uma das formas de classificação é a etiológica, dividindo-as em distonias primárias, quando não encontramos outras alterações neurológicas, além da distonia, e nem identificamos um fator causal, e distonias secundárias, quando podemos encontrar outros sintomas, além da distonia, ou identificamos um fator causal. Ambos os grupos podem ou não apresentar história familiar. O recente avanço das técnicas de biologia molecular vem permitindo uma caracterização genética mais precisa de alguns tipos hereditários de distonia. Hoje, sabemos que muitos casos esporádicos podem apresentar uma base genética. Atualmente, existe uma tendência à classificação genética das distonias. Apresentamos, a seguir, uma revisão de algumas formas hereditárias de distonia. Enfocamos particularmente aquelas que apresentam a distonia como sintoma único ou predominante.

As distonias primárias constituem um grupo geneticamente heterogêneo, embora possa ocorrer sobreposição dos fenótipos. Clinicamente, podem ser classificadas, de acordo com a idade, como de início precoce (na infância ou na adolescência) ou tardio (na idade adulta). As formas que se iniciam na infância tendem a ter um início focal em um dos membros, evoluindo posteriormente para a forma generalizada. Já as de início na idade adulta tendem a ser mais localizadas no segmento crânio-cervical e apenas uma pequena porcentagem dos pacientes evolui com generalização.

A distonia primária de início precoce, ligada ao gene DYT1, apresenta herança autossômica dominante, com maior prevalência entre os judeus Ashkenazi e com uma penetrância estimada entre $30 \%$ e $40 \%{ }^{3}$. Esses quadros 
ligados ao gene DYT1 são os que Oppenheim descreveu no início do século 20. Entre as distonias hereditárias, representa a forma mais comum e também a mais grave. Em relação à idade, apresenta uma distribuição bimodal; a maioria dos casos tem início na infância (pico de incidência aos 9 anos) e alguns casos têm início tardio (pico de incidência aos 45 anos) ${ }^{4}$. As crianças com fenótipo típico apresentam distonia inicialmente no membro inferior ou superior e progridem para a forma generalizada em um período de cinco anos, aproximadamente. Em geral, a musculatura crânio-cervical é poupada. Raramente, inicia na idade adulta e, nesse caso, a distonia concentra-se, predominantemente, no segmento crânio-cervical e não há uma tendência tão grande à generalização. A mutação no gene DYT1 do cromossomo 9 q34 foi identificada recentemente ${ }^{5}$. Trata-se de uma deleção de 3 pares de base (GAG), levando à perda da codificação de um ácido glutâmico próximo ao terminal carboxila da proteína torsina A. Essa nova proteína identificada ainda não tem função bem estabelecida. Ela liga-se ao ATP e assemelha-se à superfamília das proteínas do choque térmico e às proteases Clp. Apresenta homólogos nos nematodes, nos ratos, nos camundongos, na Drosophila, no peixe-zebra e no homem. Estudos realizados com cérebros de indivíduos normais mostram que a torsina A apresenta uma grande expressão nos neurônios dopaminérgicos da substância negra pars compacta, locus ceruleus, no núcleo denteado cerebelar, nas células de Purkinje, na base da ponte, em vários nos núcleos talâmicos, nos núcleos pedúnculo-pontinos e nos oculomotores, na formação hipocampal e no córtex frontal ${ }^{6}$. Foi demonstrada também uma intensa imunorreatividade da torsina A nos corpúsculos de Lewy, no cérebro de pacientes com doença de Parkinson, comprovada por análise anatomopatológica ${ }^{7}$. Atualmente, propõe-se que os testes genéticos sejam realizados apenas nos indivíduos cujo início do quadro deu-se antes dos 26 anos (com ou sem história familiar) ou em indivíduos com início dos sintomas após essa idade, desde que tenham história familiar positiva para distonia ${ }^{8}$.

A distonia de torção com início na idade adulta (tipo misto/DYT6) foi descrita em famílias Menonitas e os estudos de ligação apontam para um lócus na região 8p21-q22 ${ }^{9}$. Difere da forma ligada ao DYT1 por ter um início mais tardio (média de 18,9 anos) e por acometer predominantemente a musculatura crânio-cervical, já no início da doença. As formas que se iniciam com distonia em um dos membros geralmente evoluem com o acometimento crânio-cervical posteriormente, ao contrário da distonia ligada ao DYT1, que acomete menos freqüentemente essa musculatura. Também difere da forma ligada ao DYT7, na qual o envolvimento dos membros é raro. Parece seguir um padrão de herança autossômica dominante com baixa penetrância, mas o papel que esse gene pode ter nos casos esporádicos da doença só poderá ser determinado após o mapeamento do mesmo.

Leube et al. realizaram um estudo de ligação com uma família que apresentava distonia de torção focal com início na idade adulta (DYT7), de herança autossômica dominante, e encontraram relação com um lócus na região $18 \mathrm{p}^{10}$. A maioria dos membros afetados dessa família apresentava torcicolo espasmódico e um deles apresentava disfonia espasmódica. A idade de início variou entre 28 e 70 anos e os sintomas distônicos permaneceram focais ao longo de 9 anos de acompanhamento. Outras 18 famílias européias com quadro clínico semelhante foram estudadas e uma relação com o lócus 18 p foi encontrada em 15 delas ${ }^{11}$.

Ainda não está bem estabelecido se existe uma forma autossômica recessiva da distonia primária de início precoce (DYT2). Alguns casos foram descritos em famílias que apresentavam consangüinidade; o início seria mais precoce e a evolução mais grave que na forma autossômica dominante DYT $1^{12}$. Alguns autores acreditam que nessas famílias a herança seja autossômica dominante com baixa penetrância ${ }^{13}$.

Uma forma rara de distonia idiopática autossômica dominante (DYT4) foi descrita em uma família australiana ${ }^{14}$. A distonia inicia-se entre 13 e 37 anos e quase todos os casos apresentam disfonia como a manifestação inicial da doença. Alguns parentes desses indivíduos distônicos eram portadores da doença de Wilson, mas não foi encontrada uma ligação dessa forma de distonia com o lócus da doença de Wilson. O lócus do DYT4 ainda não foi mapeado.

A discinesia paroxística não-cinesigênica familiar (DYT8) caracteriza-se por ataques súbitos de movimentos distônicos ou de movimentos coréicos com duração de segundos a minutos, tendo como fatores precipitantes o consumo de álcool, de café ou de tabaco, a fome ou a fadiga. Não são desencadeados pelo movimento e raramente respondem às drogas antiepilépticas. Muller et al. observaram que esse quadro de distonia se assemelha à chamada coreoatetose/ espasticidade episódica (DYT9), ligada ao lócus $1 p^{15}$. A diferença é que, nesta última, os ataques podem ser precipitados pelo exercício físico e alguns pacientes também podem apresentar ataxia episódica e paraplegia espástica, tanto durante quanto entre os ataques de discinesia. Fink et al. realizaram estudos de ligação em 28 membros de uma família afetada pela discinesia paroxística não-cinesigênica e estabeleceram uma 
relação com o cromossomo 2q33-q35; o padrão de herança é autossômico dominante ${ }^{16}$. Observaram, também, que outras patologias neurológicas paroxísticas, como as paralisias periódicas hipo e hipercalêmica, devem-se a mutações em genes de canais iônicos e que um cluster de genes de canais de sódio está localizado na região distal do cromossomo 2.

Os ataques de distonia/coréia são breves na discinesia paroxística cinesigênica familiar (DYT10), podem ocorrer diariamente, são desencadeados pelo movimento e respondem bem às drogas antiepilépticas. Estudos em uma família japonesa com padrão de herança autossômica dominante mostraram ligação com o lócus 16p11.2-q12.1 ${ }^{17}$.

Entre as distonias secundárias, uma das mais características é a distonia doparresponsiva (DYT5) descrita por Segawa ${ }^{18}$. Caracteriza-se pelo início na infância, com distonia em um dos membros, evoluindo para distonia generalizada dentro de 5 anos, em média. Os sintomas costumam piorar ao longo do dia e melhorar com o sono. Alguns casos podem cursar com sinais parkinsonianos. O que distingue essa síndrome das formas de distonia-parkinsonismo, com início na infância, é a sua dramática resposta a baixas doses de levodopa, sem o aparecimento de discinesias tardias pela droga. A maioria dos casos apresenta herança autossômica dominante, com penetrância estimada em $31 \%$. O sexo feminino tende a ser acometido com maior freqüência que o masculino. $\mathrm{Na}$ forma autossômica dominante da doença, encontramos mais de um tipo de mutação no gene da GTP ciclo-hidrolase I, no cromossomo $14 q^{19,20}$. A forma autossômica recessiva da doença, mais rara, está ligada à mutação no gene da tirosina hidroxilase no cromossomo $11^{21}$. Ambas as formas irão determinar um distúrbio na síntese de dopamina.

A distonia de torção ligada ao cromossomo $\mathrm{X}$ (DYT3) é encontrada em algumas famílias das ilhas Panay, nas Filipinas ${ }^{22}$. A herança é recessiva, acomete predominantemente o sexo masculino (só há relato de um caso no sexo feminino), a idade de início varia de 12 a 56 anos, alguns pacientes inauguram o quadro com blefaroespasmo, há tendência em evoluir para distonia generalizada com o passar dos anos e podem surgir sinais parkinsonianos até mesmo antes da distonia. O lócus foi identificado na região Xq13.123.

Em 1993, foi descrita uma forma familiar de distonia denominada distonia-parkinsonismo de início rápido ${ }^{24}$. O padrão de herança é autossômico dominante e a doença afeta indivíduos entre 14 e 45 anos. É peculiarm, nessa síndrome, seu quadro de início relativamente súbito com distonia e parkinsonismo, algumas vezes se instalando rapidamente, em horas ou em semanas e, a partir de então, o curso passa a ser lento. A terapia dopaminérgica não é eficaz nesses casos. O lócus genético ainda não foi determinado.

Como vimos, houve um grande avanço no conhecimento da genética molecular das síndromes distônicas, particularmente nos últimos 5 anos. O diagnóstico genético preciso das diversas formas de distonia irá possibilitar uma maior compreensão sobre os mecanismos fisiopatológicos dessas doenças, podendo levar ao desenvolvimento de terapêuticas mais eficazes do ponto de vista sintomático e até mesmo preventivo e curativo.

\section{SUMMARY}

\section{Genetics of Dystonia}

The dystonic syndromes have a great clinical and genetic heterogeneity. There is an increasing tendency towards a genetic classification of the hereditary forms of dystonia. With the improvement of the molecular biology techniques some types of dystonia genes have already been mapped, such as the primary torsion dystonia-DYT1 and dystonia genes. We present a brief review of clinical and genetic aspects of some of the inherited forms of dystonia, particularly those where dystonia is the only or the main symptom.

\section{KEYWORDS}

Dystonia, genetic, DYT1, dopa-responsive dystonia

\section{Referências}

1. Fahn S, Marsden CD, Calne DB. Classification and investigation of dystonia. In: Marsden CD, Fahn S, (eds.). Movement disorders 2. London, Butterwoths, 1987, 332-58.

2. Oppenheim $\mathrm{H}$. Uber eine eigenartige kramfkrankheit des kindlichen und jugendlichen alters (dysbasia lordotica progressiva, dystonia musculorum deformans). Neurol Centrabl, 30:1090-107, 1911.

3. Kramer PL, Heiman GA, Gasser LJ, Ozelius LJ, de Leon D, Brin MF, Burke RE, Hewett J, Hunt AL, Moskowitz C, Nygaard TG, Wihelmsen KC, Fahn S, Breakefield XO, Risch NJ, Bressman SB. The DYT1 gene on 9q34 is responsible for most cases of early limb-onset idiopathic torsion dystonia in non-jews. Am J Genet, 55:468-75, 1994.

4. Bressman SB, de Leon D, Brin MF. The pattern of inheritance of dystonia among Ashkenazi jews. Adv Neurol, 50:45-56, 1988.

5. Ozelius LJ, Hewett JW, Page CE et al. The early-onset torsion dystonia gene (DYT1) encodes an ATP-binding protein. Nature Genetics, 17:40-8, 1997.

6. Augood SJ, Martin DM, Ozelius LJ, Breakefield XO, Penney Jr JB, Standaert DG. Distribuition of the mRNAs enconding torsin- $A$ and torsin-B in the normal adult human brain. Ann Neurol, 6:761-9, 1999.

7. Shashidharan P, Good PF, Walker RH, Hsu A, Perl DP, Olanow CW, Brin MF. Immunoreactivity of torsin-A in normal human brain and in Lewy bodies of Parkinson's disease brain. Soc Neurosci Abstracts, 25:2115, 1999.

8. Bressman SB, Sabatti C, Raymond D, de Leon D, Klein C, Kramer PL, Brin MF, Fahn S, Breakefield X, Ozelius LJ, Risch NJ. The DYT1 phenotype and guidelines for diagnostic testing. Neurology, 54:1746-52, 2000.

9. Almasy L, Bressman SB, Kramer PL, Greene PE, Heiman GA, Ford B, Yount J, de Leon D, Chouinard S, SaundersPullman R, Brin MF, Kapoor RP, Jones AC, Shen H,Fahn S, Risch NJ, Nygaard TG. Idiopathic torsion dystonia linked to chromosome 8 in two Mennonite families. Ann Neurol, 42:670-3, 1997. 
10. Leube B, Doda R, Rudinicki D, Ratzlaff T, Kessler KR, Beneccke R, Auburger G. Idiopathic torsion dystonia: assignment of a gene to cromosome $18 p$ in a german family with adult onset, autosomal dominant inheritance and purely focal distribution. Hum Molec Genet, 5:1673-7, 1996.

11. Leube B, Hendgen T, Kessler KR, Knapp M, Beneccke R, Auburger G. Evidence for DYT7 being a common cause of cervical dystonia (torticollis) in central Europe. Am J Med Genet, 74:529-32, 1997.

12. Eldridge R. The torsion dystonias: literature review and genetic and clinical studies. Neurology, 20:1-78, 1970.

13. Korczyn AD, Kahana E, Zilber N, Streifler M, Carasso R, Alter M. Torsion dystonia in Israel. Ann Neurol, 8:387-91, 1980.

14. Ahmad F, Davis MB, Waddy HM, Oley CA, Marsden CD, Harding AE. Evidence of locus heterogeneity in autosomal dominant torsion dystonia. Genomics, 15:9-12, 1993.

15. Muller U, Steinberger D, Nemeth AH. Clinical and molecular genetics of primary torsion dystonias. Neurogenetics, 1:16577, 1998.

16. Fink JK, Rainer S, Wilkowski J, Jones SM, Kume A, Hedera P, Albin R, Mathay J, Girbach L, Varvil T, Otterud B, Leppert M. Paroxysmal dystonic choreoathetosis: tight linkage to chromosome 2q. Am J Hum Genet, 59:140-5, 1996.

17. Tomita H, Nagamitsu S, Wakui K, Fukushima Y, Yamada K, Sadamatsu M, Masui A, Konishi T, Matsuishi T, Aihara M, Shimizu K, Hashimoto K, Mineta M, Matsushima M, Tsujita T, Saito M, Tanaka H, Tsuji S, Takagi T, Nakamura Y, Nanko $\mathrm{S}$, Kato N, Nakane Y, Niikawa N. Paroxysmal kinesigenic choreoathetosis locus maps to chromosome 16p11.2-q12.1. Am J Hum Genet, 65:1688-97, 1999.

18. Segawa M, Hosaka A, Miyagwa F, Nomura $Y$, Imai H. Hereditary progressive dystonia with marked diurnal fluctuation. Adv Neurol, 14:215-33, 1976.
19. Nygaard TD, Wilhelmsen KC, Risch NJ, Brown DL, Trugman JM, Gilliam TC, Fahn S, Weeks DE. Linkage mapping of dopa-responsive dystonia (DRD) to chromosome 14q. Nature Genet, 5:386-91, 1993.

20. Ichinose H, Ohye T, Takahashi E, Seki N, Hori T, Segawa M, Nomura Y, Endo K, Tanaka H, Tsuji S, Fujita K, Nagatsu T. Hereditary progressive dystonia with marked diurnal fluctuation caused by mutations in the GTP cyclohydrolase I gene. Nature Genet, 8:236-42, 1994.

21. Ludecke B, Dworniczak B, Bartholome K. A point mutation in the tyrosine hydroxylase gene associated with Segawa's syndrome. Hum Genet, 95:123-5, 1995.

22. Kupke K, Lee LV, Viterbo GH, Arancillo J, Donlon T, Muller $\mathrm{U}$. X-linked recessive torsion dystonia in the Philippines. Am J Med Genet, 36:237-42, 1990.

23. Harbernhausen G, Schimitt I, Kohler A, Peters U, Rider S, Chelly J, Terwilliger JD, Monaco AP, Muller U. Assignment of the dystonia-parkinsonism syndrome locus, DYT3, to a small region within a 1.8-Mb YAC contig of Xq13.1. Am J Hum Genet, 57:644-50, 1995.

24. Dobyns WB, Ozelius LJ, Kramer PL, Brashear A, Farlow MR, Perry TR, Walsh LE, Kasarskis EJ, Butler IJ, Breakefield XO. Rapid onset dystonia-parkinsonism. Neurology, 43:2596602, 1993.

\section{Endereço para correspondência:}

Escola Paulista de Medicina Disciplina de Neurologia

Rua Botucatu, 740 - Vila Clementino CEP 04023-900 - São Paulo, SP E-mail: henrique@sun-nepi.epm.br 